\title{
"O rouge virou blush". Será, Veríssimo? O que nos dizem os dados do Atlas Linguístico do Brasil/Centro-Oeste
}

\author{
Daniela de Souza Silva Costa \\ Universidade Federal de Mato Grosso do Sul (UFMS), Aquidauana, Mato Grosso do Sul, Brasil \\ danielassilva@hotmail.com
}

DOI: http://dx.doi.org/10.21165/el.v46i1.1756

\begin{abstract}
Resumo
Tendo por base a teoria do Relativismo Linguístico Sapir-Whorf, entendemos a língua como objeto social, meio pelo qual os homens, além de transmitir crenças, hábitos e conhecimentos, também compreendem sua realidade e mesmo a transformam. Nesse sentido, este estudo discute traços da realidade linguística do Centro-Oeste a partir dos nomes para rouge/blush proferidos pelos informantes do Projeto Atlas Linguístico do Brasil entrevistados em 21 localidades do interior e também nas três capitais de Estados dessa região, tendo por base o aporte teórico da Lexicologia, da Dialetologia e da Geolinguística. Como objetivos do trabalho, busca-se compreender como a realidade linguística pode revelar características como relações sociais e aspectos sócio-histórico-econômicos da comunidade em questão, além de se ratificar a importância dos estudos lexicais para o (re)conhecimento de realidades linguísticas em determinado tempo e espaço, aqui representados pelo Centro-Oeste no limiar do século XXI.
\end{abstract}

Palavras-chave: norma linguística; centro-oeste; rouge; Projeto ALiB.

\section{"The rouge turned blush". Is it true, Veríssimo? What data from Linguistic Atlas of Brazil/Brazilian Midwest Region say to us}

\begin{abstract}
Based on the theory of Sapir-Whorf Linguistic Relativity, we understand the language as a social object, the mean by which men, in addition to transmit beliefs, habits and knowledge, also see their reality and even transform it. In this sense, this study discusses the linguistic reality traces of the Brazilian Midwest Region from the names to rouge/blush cast by Linguistic Atlas Project of Brazil informants interviewed in 21 localities of the countryside and also in the three state capitals of the region, based on the theoretical framework of Lexicology, Dialectology and Geolinguistics. As objectives of the work, we seek to comprehend how the linguistic reality can reveal features such as social relationships, socio-historical and economic aspects of the community in question, and to confirm the importance of lexical studies for the acceptance of linguistic realities in a given time and space, here represented by the Midwest in the XXI century threshold.
\end{abstract}

Keywords: linguistic norm; Brazilian Midwest Region; rouge; ALiB Project. 


\title{
Introdução
}

\author{
"O rouge virou blush \\ O pó-de-arroz virou pó-compacto \\ O brilho virou gloss" \\ Luis Fernando Veríssimo
}

Esta epígrafe é parte de uma crônica de Veríssimo que revela o lirismo visto a partir da ótica poética presente nas mudanças linguísticas e, por isso, foi escolhida para introduzir este artigo. Além disso, trata diretamente do referente a que se reporta este trabalho, especialmente no que tange a suas hipóteses, bem como a alguns resultados de estudos anteriores, como será visto no seguimento do texto.

Concordamos com o eu-lírico que vê a mudança da sociedade a partir das variações linguísticas que ocorrem no decurso do tempo, por exemplo. Isso porque toda língua traz consigo a realidade da comunidade que a utiliza, haja vista refletir os modos de ser, de viver e de pensar desse grupo, e até mesmo por organizar pensamentos e conhecimentos do homem. Mesmo não sendo consenso entre os linguistas, o princípio teórico do Relativismo Linguístico, advindo da denominada hipótese Sapir-Whorf, subsídio dessa afirmação bem como deste trabalho como um todo, é aceita na comunidade acadêmica, até por responder a inquietações dos estudos linguísticos que encontram achados, muitas vezes, reveladores das alterações na norma linguística. Isso porque "[...] todo sistema lingüístico manifesta, tanto no seu léxico como na sua gramática, uma classificação e uma ordenação dos dados da realidade que são típicas dessa língua e da cultura com que ela se conjuga" (BIDERMAN, 1998, p. 93).

Nesse sentido, mudanças na organização social de uma comunidade podem se refletir na língua em uso num dado momento sócio-histórico, especialmente no nível lexical, responsável pela nomeação dos elementos que compõem toda a vida circundante do homem.

Nessa seara, recuperando as palavras de Lucchesi (1998, p. 95), “[...] as mudanças na língua seriam, em sua maioria, uma resposta às novas exigências de expressão, decorrentes das alterações no universo cultural da comunidade linguística, das descobertas científicas e tecnológicas etc.”. E essas mudanças linguísticas foram especialmente consideradas nos estudos de William Labov (1972), por meio da Sociolinguística Variacionista.

Mas o que dizer da não-mudança linguística? $\mathrm{O}$ que pensar quando certas comunidades, em detrimento do movimento que uma norma linguística apresenta em busca de mudanças que atendam a novas exigências sociais, mostram-se, pelo menos, incólumes a essas variações?

Também a Sociolinguística, associada à Dialetologia, busca respostas para essas perguntas, tendo em vista que a solução para o entendimento da não-mudança pode residir exatamente na relação entre léxico e sociedade, léxico e cultura.

Considerando o exposto, este artigo busca discutir a relação entre léxico, cultura e sociedade por meio do exame de dados do Projeto Atlas Linguístico do Brasil concernentes aos inquéritos realizados na região Centro-Oeste brasileira em 24 cidades, 
localidades do interior e capitais dos três Estados: Mato Grosso, Mato Grosso do Sul e Goiás, no que diz respeito aos nomes dados a "aquilo que as mulheres passam no rosto, nas bochechas, para ficarem mais rosadas" (COMITE NACIONAL DO PROJETO ALIB, 2001, p. 37). Com vistas a atingir esse objetivo, o trabalho analisa as unidades lexicais catalogadas sob as perspectivas diatópica e léxico-semântica, buscando motivações em fatores sociais, econômicos e culturais.

\section{Fundamentação teórica e metodológica}

Considerando-se que "cada língua traduz o mundo e a realidade social segundo o seu próprio modelo, refletindo uma cosmovisão que lhe é própria, expressa nas suas categorias gramaticais e léxicas" (BIDERMAN, 1978, p. 80), reportamo-nos à hipótese do Relativismo Linguístico, proposta inicialmente por Edward Sapir e Benjamin Lee Whorf, pesquisadores norte-americanos que defendiam a tese de que, por meio da língua, as ideias eram formadas e organizadas para também serem expressas. Nesse sentido:

[...] Qualquer sistema léxico é a somatória de toda a experiência acumulada de uma sociedade e do acervo da sua cultura através das idades. Os membros dessa sociedade funcionam como sujeitos-agentes, no processo de perpetuação e reelaboração contínua do Léxico da sua língua. (BIDERMAN, 1978, p. 139).

Partindo desse pressuposto, concebemos a língua, e mais especificamente o léxico, como produto social, cujo estudo pode propiciar um maior conhecimento da realidade linguística e também da sociedade num dado momento histórico. E, com o intuito de compreender fatos linguísticos considerando-se também aspectos extralinguísticos, nosso aporte teórico contempla, além da Semântica e da Lexicologia, também a Sociolinguística, a Dialetologia e a Geolinguística, cujo objeto de investigação, grosso modo, é a língua e seus usos.

Enquanto a Semântica, no caso a lexical, estuda os sentidos das palavras ${ }^{1}$ e a Lexicologia investiga a origem e as transformações fonéticas, morfológicas, sintáticas e semânticas dos itens lexicais, a Dialetologia é o "ramo dos estudos da ciência da linguagem que se ocupa da variação e da diversidade de usos" (CARDOSO, 2008, p. 16). Essa variação, bem como a diversidade de usos mencionada, é motivada por vários fatores, muitos deles extralinguísticos, como o espaço social e geográfico em que a língua se insere. $\mathrm{O}$ espaço geográfico, pois, tem lugar nos estudos dialetais haja vista que:

[...] Evidencia a particularidade de cada terra, exibindo a variedade que a língua assume de uma região para outra, como forma de responder à diversidade cultural, à natureza da formação demográfica da área, à própria base linguística preexistente e à interferência de outras línguas que se tenham feito presentes naquele espaço no curso da história. (CARDOSO, 2010, p. 15).

\footnotetext{
${ }^{1}$ Usamos aqui um conceito de palavra da Semântica Lexical presente em Tamba (2006, p. 70): "numa primeira aproximação, as palavras são um conjunto de formas fônicas e gráficas autônomas, estáveis, que constituem o léxico de uma língua”.
} 
Dessa maneira, os estudos dialetológicos servem-se do aporte da Geolinguística para a cartografação de seus dados também com o auxílio das informações de quem as fornece, de acordo com perfis específicos ${ }^{2}$ e em espaços determinados:

[...] Na geolinguística pluridimensional contemporânea, soma-se ao parâmetro diatópico, prioritário em trabalhos dessa natureza, o interesse por outros tipos de variação, como a diagenérica [variação entre os gêneros/sexos masculino e feminino], a diastrática [variantes sociais], a diageracional [considerando-se a idade dos falantes], entre outras. (MOTA; CARDOSO, 2006, p. 22).

Assim, estudos dialetológicos e sociolinguísticos aproximam-se sobremaneira, tendo em vista que ambas as disciplinas tratam da variação linguística, porém sob perspectivas diferentes. A Sociolinguística ocupa-se da relação entre língua e sociedade, entre a língua e seu uso. Considera, por exemplo:

[...] [Que] dois falantes de uma mesma língua ou variedade dialetal dificilmente se expressam exatamente do mesmo modo, assim como um único falante raramente se expressa da mesma maneira em duas diferentes circunstâncias de comunicação [...]. [O que a] Sociolingüística faz é correlacionar as variações existentes na expressão verbal a diferenças de natureza social, entendendo cada domínio, o lingüístico e o social, como fenômenos estruturados e regulares. (CAMACHO, 2005, p. 50).

No caso deste texto, mais especialmente, utilizamos o princípio sociolinguístico das Redes Sociais, herança da Antropologia Cultural e da Psicologia Social. Segundo Bortoni-Ricardo (2014, p. 130), “[...] uma rede social é concebida como o conjunto de vínculos de qualquer tipo que se estabelecem entre as pessoas de um grupo [...] [e] as características desses vínculos podem ser muito reveladoras das identidades dos membros do grupo".

Nota-se, pois, que os estudos que partem da relação entre língua e sociedade podem contribuir para a compreensão de diversos fatos linguísticos, uma vez que comunidades sociais distintas acabam por diferenciar também suas normas linguísticas, mesmo em um único macroespaço geopolítico, como é o caso do Brasil.

Nesse país de dimensões continentais, pesquisas têm demonstrado a riqueza linguística advinda das diferentes realidades das regiões brasileiras, como se pretende fazer neste trabalho. O Atlas Linguístico do Brasil, por exemplo, projeto de cunho geolinguístico que documenta a norma linguística em uso pelos brasileiros neste século, já tem dado mostras da referida riqueza.

O Projeto Atlas Linguístico do Brasil (Projeto ALiB) - empreendimento de grande amplitude, de caráter nacional, em desenvolvimento - tem por meta a realização de um atlas geral do Brasil no que diz respeito à língua portuguesa. Desejo que permeia a

\footnotetext{
${ }^{2} \mathrm{O}$ método geolinguístico orienta que apenas dados linguísticos advindos de pesquisas com mesma metodologia são passíveis de uma análise contrastiva coerente. Nesse sentido, o Projeto ALiB adota um questionário único aplicado a todos os inquéritos - composto por 431 questões que contemplam realizações fonético-fonológicas (159 perguntas); prosódicas (11 questões); semântico-lexicais - 14 áreas semânticas (202 perguntas); morfossintáticas (49 questões); pragmáticas (quatro perguntas) e metalinguísticas (seis perguntas), além de quatro temas para discursos semidirigidos e um texto para leitura. Quanto ao perfil dos entrevistados, estes devem ser naturais da localidade e filhos de pais oriundos da mesma região linguística, homens e mulheres, de duas faixas etárias (18 a 30 e 50 a 65 anos), com escolaridade fundamental (interior e capitais) e universitária (capitais).
} 
atividade dialetal no Brasil, durante todo o desenvolvimento dos estudos linguísticos e filológicos, ganha corpo nesse final/começo de milênio, a partir de iniciativa de um grupo de pesquisadores [...] que envolve hoje doze Universidades (PROJETO ALIB, 2016).

Nos primeiros volumes do ALiB publicados em 2014 (CARDOSO et al., 2014), pode-se confirmar a importância da variação, tanto fonética quanto lexical, na constituição da variante brasileira do português, e esse Projeto também subsidia este trabalho, fornecendo os dados em tela, bem como a metodologia utilizada nas análises.

Assim, a continuidade deste texto dá-se com a apresentação e a análise de dados dos pontos de vista diatópico e léxico-semântico com o intuito de compreender aspectos da realidade linguística da região Centro-Oeste por meio das informações ora analisadas, bem como intenta entender como fatores políticos, econômicos e sociais refletem-se na seleção lexical dos falantes.

\section{Apresentação e análise de dados}

Ao examinarmos os inquéritos realizados pelo Projeto ALiB com os 108 informantes das capitais e das localidades do interior dos estados ${ }^{3}$ que compõem a região Centro-Oeste, registramos quatro unidades lexicais" para designar "aquilo que as mulheres passam no rosto, nas bochechas, para ficarem mais rosadas" (COMITE NACIONAL DO PROJETO ALIB, 2001, p. 37): rouge, blush/bronze e carmim. ${ }^{5}$

Sob a perspectiva lexicográfica, rouge encontra-se dicionarizado em Houaiss (2001) como "pó ou pasta, de tonalidade entre o rosa e o vermelho, que se espalha nas maçãs do rosto", definição semelhante à encontrada em Caldas Aulete (2006). Segundo essas mesmas obras, deriva do francês rouge, " "que tem a cor característica do sangue, de certas flores'; s.m. 'colorante vermelho"' (HOUAISS, 2001), dicionário este que ainda oferece a datação desta unidade léxica em português como do ano de 1130.

Blush, por sua vez, é definido como o "cosmético em pó ou creme, usado para corar a face; rouge" (HOUAISS, 2001), advindo do inglês e datado, em língua portuguesa, do ano de 1969. Bronze, que foi associado a blush, significa "substância, por exemplo, pigmento, pó ou tintura, para dar a uma superfície uma aparência brônzea ou de outro metal brilhante". Fizemos a associação entre ambas as variantes léxicas por compreender a segunda como uma provável derivação da primeira, ou também pelo fato de bronze se tratar de outra unidade léxica que, por analogia entre as cores, foi associada a blush, rouge, calcando-nos também na dúvida do informante que a mencionou na fala. ${ }^{6}$

\footnotetext{
3 A partir da metodologia adotada pelo Projeto ALiB, compõem seu quadro de informantes quatro indivíduos com Ensino Fundamental em cada localidade, interior e capitais, e mais quatro em cada capital (nível universitário).

${ }^{4}$ A ordem na apresentação dos itens respeitou a produtividade (número de ocorrências) das respostas.

${ }^{5}$ Houve ainda uma ocorrência de ruivo, mas não consideramos essa variante neste estudo por não dizer respeito ao referente em pauta.

${ }^{6}$ Depois de responder bronze, ao ser perguntado novamente sobre o nome para o referente em questão, o informante jovem de escolaridade ensino fundamental morador de Alto Araguaia (MT) respondeu: "Bronze, bronze, não sei, blog eu não lembro isso".
} 
Carmim, a última unidade lexical analisada sob o viés léxico-semântico, advém do étimo de origem francesa carmin e significa "matéria corante, de um vermelho muito vivo, extraída, originalmente, da cochonilha-do-carmim" (CUNHA, 2010), sendo datada de 1615 (HOUAISS, 2001). Esta obra fornece a informação de ser a "cor desse corante; carmesin, magenta", registrando ainda que se trata de "voc. consid. gal. pelos puristas, que sugeriram em seu lugar: carmim". Entretanto, além dessas informações, o Dicionário da Língua Portuguesa Contemporânea acrescenta-lhe tratar-se da própria "maquilagem líquida ou sólida, de cor vermelha, constituída por um corante neutro numa base gordurosa" (ACADEMIA DAS CIÊNCIAS DE LISBOA, 2001).

Nota-se, pois, que carmim, que designa a base do cosmético em pauta na questão 191 do Questionário Semântico-lexical do Projeto ALiB (2001), ainda se refere à maquiagem cujos nomes estão sendo por este trabalho analisados, fato provavelmente motivado por um processo metonímico em que o item lexical passou a nomear não apenas a substância componente, mas também o próprio produto. Confirma essa afirmação a referência que a informante campo-grandense de escolaridade universitária e pertencente à faixa etária II forneceu: depois de responder rouge como sua resposta para a pergunta, ela fala que antigamente o nome era carmim, "[...] carmim... vô passá carmim pra í na festa, a minha vó falava. Eu lembro" (INF08/115), mostrando que essa designação já esteve presente em outro momento histórico da língua portuguesa, permanecendo em uso por pessoas mais velhas e, talvez por esse motivo, caindo em desuso ao menos no Centro-Oeste, região dos dados em análise.

No que diz respeito ao viés dialetológico e geolinguístico, as considerações acerca das unidades aqui consideradas antigas (dada sua datação), mas ainda presentes na fala do Brasil Central, encontram reforço em estudos já realizados anteriormente.

Paim e Guimarães (2012), por exemplo, associaram a variante lexical rouge aos falantes idosos, predominantemente, inclusive, em sua pesquisa que teve por base dados do Projeto Atlas Linguístico do Brasil coletados nas 25 capitais brasileiras. Para os pesquisadores, mesmo os falantes assim identificam suas respostas, dentre outros:

Os informantes da faixa II do Projeto ALiB podem ser considerados como idosos/velhos pelo próprio sentimento dos indivíduos dessa faixa, que se veem e creem como velhos, como ilustram as passagens: "[...] Hoje chama blush, no meu tempo era rouge" (Salvador, Mulher, 54 anos) (PAIM; GUIMARÃES, 2012, p. 304).

Rouge parece, pois, possuir uma marca diageracional a partir do compreendido pelo trecho acima, o que se confirma pelos dados do volume II do Atlas Linguístico do Brasil, que elucida: "[...] a denominação rouge foi registrada no discurso da maioria dos informantes das capitais brasileiras como uma variante típica de pessoas mais velhas" (CARDOSO et al., 2014, p. 334), além de essa mesma publicação relacionar as ocorrências de tal unidade léxica ao nível de escolaridade dos falantes na Carta L26 concernente ao rouge, uma vez que está fortemente presente na fala daqueles que têm ensino fundamental, sendo, contudo, a mais produtiva no universo das capitais brasileiras (CARDOSO et al., 2014). Essa predominância confirma-se também nos dados analisados por este estudo, como pode ser visualizado pelo Gráfico 1: 


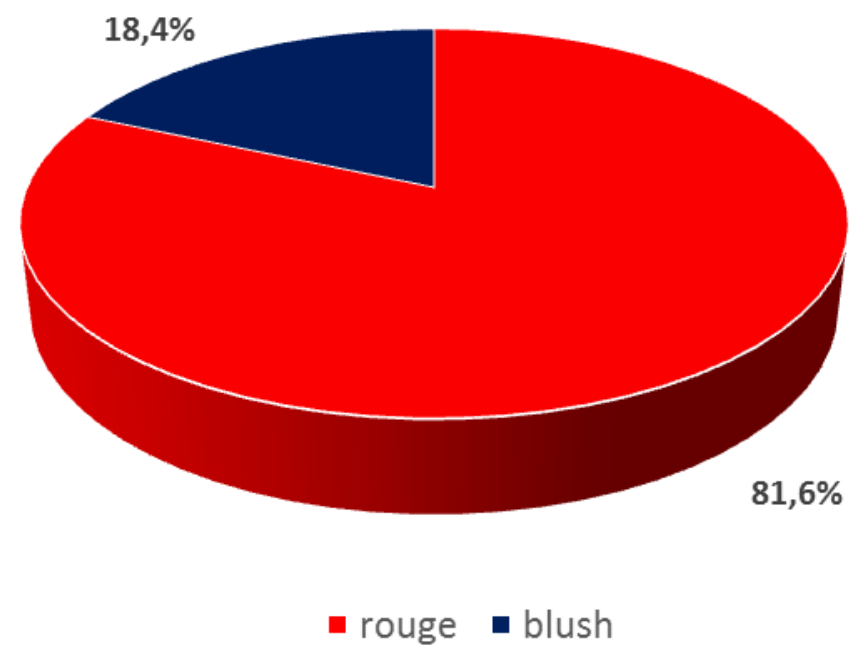

Gráfico 1. Produtividade dos designativos para "aquilo que as mulheres passam no rosto, na bochecha, para ficarem rosadas" nas localidades do Centro-Oeste/Projeto $\mathbf{A L i B}^{7}$

Fonte: Banco de Dados do ALiB. Elaborado pela autora

Com vistas a analisar a produtividade de rouge e blush $^{8}$ de acordo com a perspectiva diatópica, elaboramos o Gráfico 2:

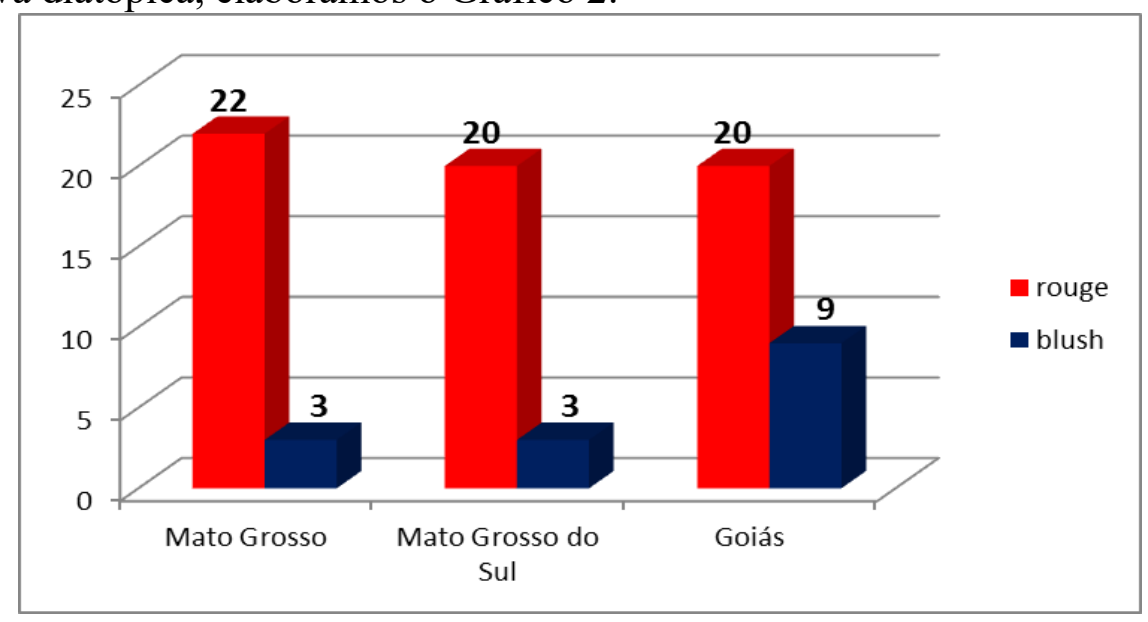

Gráfico 2. Produtividade das unidades léxicas rouge e blush segundo os estados do Centro-Oeste/Projeto ALiB

Fonte: Banco de Dados do ALiB. Elaborado pela autora

\footnotetext{
${ }^{7}$ No Gráfico 1, foram apresentadas apenas as unidades léxicas resultantes de respostas válidas para a pergunta que as gerou. Dentre as não válidas, foram documentadas as designações pó, maquiagem e creme. Além dessas, não foram computadas as ausências de resposta, que, no universo dos dados ora analisados, contou 21 ocorrências.

${ }^{8}$ Haja vista que o item lexical carmim foi ocorrência única, optamos por não o representar na análise diatópica.
} 
Os dados gerais representados pelos Gráficos 1 e 2 demonstram a marcante presença de rouge, cuja soma de ocorrências é mais que o quádruplo de blush, a segunda variante léxica mais documentada (62 ocorrências de rouge - 81,6\% - e 14 de blush - 18,4\%).

Se separarmos esses dados segundo o grau de escolaridade dos falantes - mesmo porque não podemos perder de vista que o nível universitário só é contemplado nas capitais de Estado, diferentemente do nível fundamental de escolaridade, presente em todas as localidades pesquisadas - veremos, mesmo assim, que o padrão de predominância do item léxico rouge frente à unidade lexical de segunda maior ocorrência, blush, mantém-se:

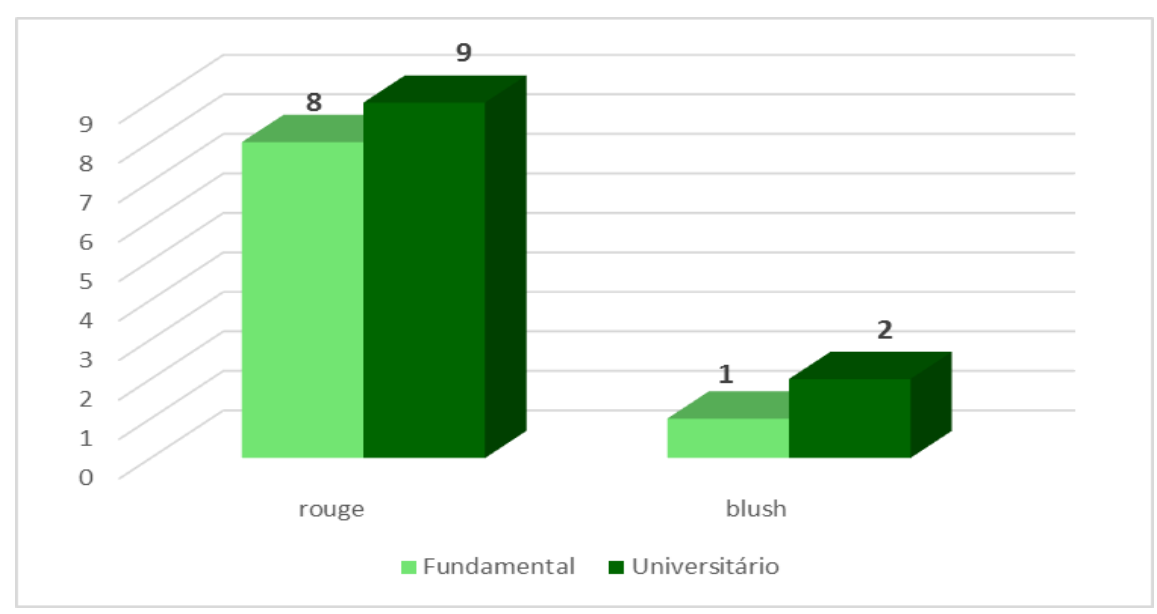

Gráfico 3. Produtividade de rouge e blush de acordo com o grau de escolaridade dos informantes ALiB das capitais do Centro-Oeste brasileiro

Fonte: Banco de Dados do ALiB. Elaborado pela autora

Já ao analisar separadamente dados das capitais e do interior, teremos o seguinte resultado, representados pelo Gráfico 4 os dados das capitais e, pelo Gráfico 5, os referentes às localidades do interior:

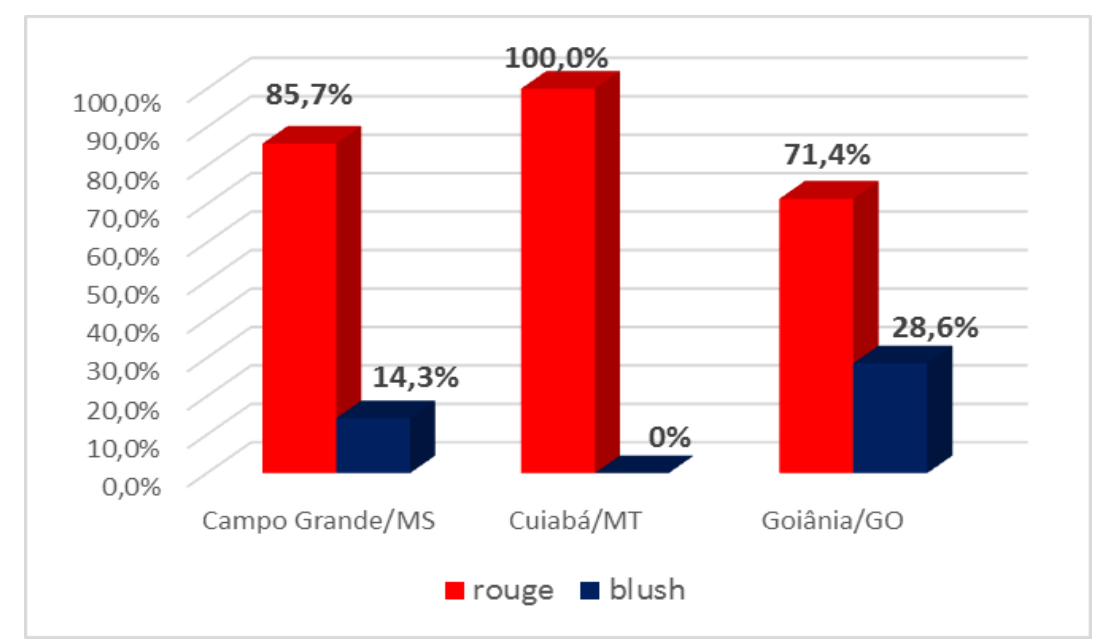

Gráfico 4. Produtividade de rouge e blush nas capitais do Centro-Oeste brasileiro/Projeto ALiB

Fonte: Banco de Dados do ALiB. Elaborado pela autora 


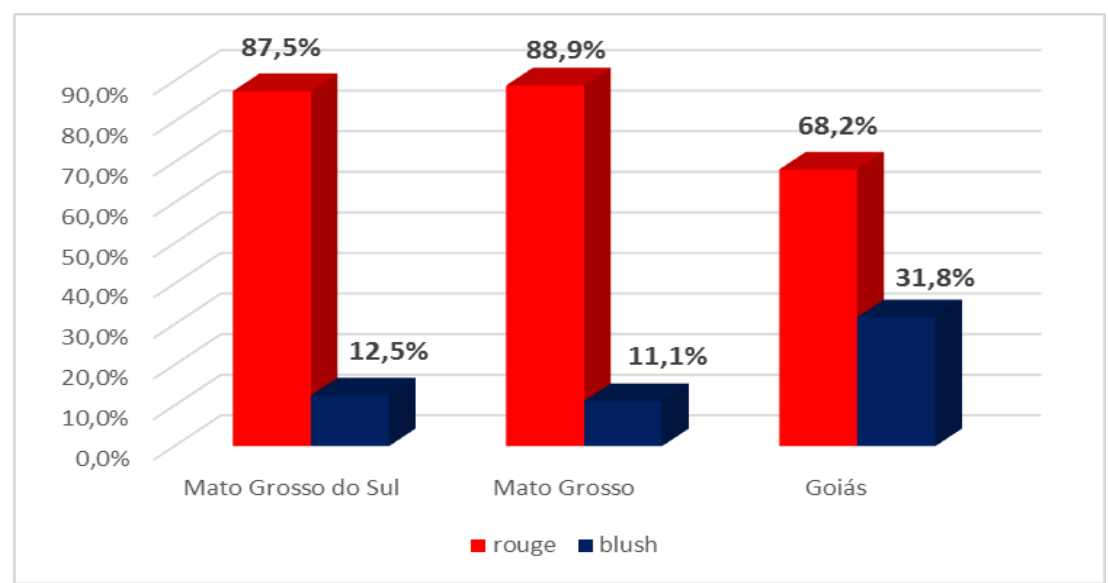

Gráfico 5. Produtividade de rouge e blush em localidades do interior do Centro-Oeste brasileiro/Projeto ALiB

Fonte: Banco de Dados do ALiB. Elaborado pela autora

Vemos, a partir dos Gráficos 4 e 5, que tanto as capitais quanto o interior dos estados do Centro-Oeste mantêm aproximações quanto às ocorrências das unidades léxicas em análise, bem como à proporção entre elas. Uma pequena variação é verificada em Goiás, tanto em sua capital, Goiânia, quanto nas oito localidades do interior: a diferença entre os registros de rouge e blush torna-se menor frente aos outros estados (15 ocorrências de rouge para sete de blush no interior e cinco para dois na capital). O estado de Goiás pode ter justificada essa diferença frente aos demais do Brasil Central devido ao seu histórico de povoamento, uma vez que, diferentemente dos mineiros, paulistas, nordestinos, gaúchos, dentre outros, que povoaram terras matogrossenses e sul-mato-grossenses, destaca-se a presença nordestina em Goiás, que chegou em meados da década de 1960 para a construção de Brasília (FAUSTO, 2009) e ali permaneceu no cultivo de grãos e na lida de gado (SANDES, 2002).

Frente ao exposto, nossas análises serão direcionadas agora apenas aos dados dos informantes cuja escolaridade seja de Ensino Fundamental, uma vez que, como já mencionado, a educação universitária é apenas contemplada nas capitais de Estados, de acordo com a metodologia do Projeto $\mathrm{ALiB}$, o que impossibilita uma comparação metodologicamente coerente entre os oito informantes de cada capital e os apenas quatro das localidades do interior. Mesmo tomando-se apenas os informantes de nível de escolaridade fundamental em todas as localidades pesquisadas, o panorama não se altera substancialmente, aumentando-se, inclusive, a predominância do item mais documentado: 


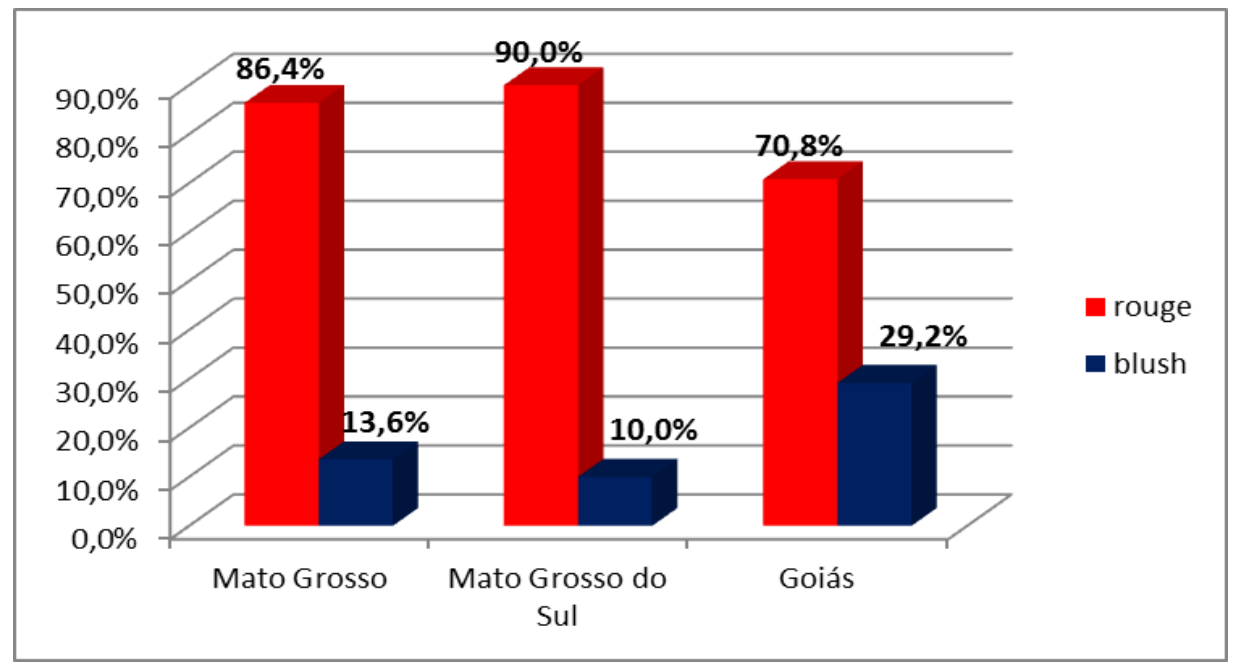

Gráfico 6. Produtividade de rouge e blush no interior do Centro-Oeste/Projeto ALiB, nível de escolaridade fundamental dos informantes

Fonte: Banco de Dados do ALiB. Elaborado pela autora

A partir da análise dos gráficos, podemos questionar o que leva a região CentroOeste a manter, na língua em uso, palavras cuja datação se remete a fases anteriores da língua. Esse questionamento encontra reforço mesmo nas capitais dessa região, tendo em vista que, se considerarmos os dados fornecidos por falantes com formação universitária de Cuiabá, Campo Grande e Goiás, ainda assim temos o domínio de rouge frente a blush (81,6\% e 18,4\% das ocorrências, respectivamente).

Isso pode demonstrar certo conservadorismo linguístico. ${ }^{9}$ Em sentido mais amplo, podemos entender o conservadorismo como traços da língua característicos do português arcaico (MELO, 1971), "[...] os quais já foram inovados no português europeu e em alguns padrões linguísticos urbanos do Brasil” (SANTOS, 2008, p. 241).

Talvez o relativo isolamento sociocultural, tendo em vista o distanciamento não tanto geográfico quanto histórico e econômico dessa região dos polos socioeconômicos do país, como São Paulo, por exemplo, aliado às condições geográficas da área, que por sua vez geram uma economia baseada especialmente na agropecuária e no extrativismo, pode explicar esse isolamento também linguístico tanto nas localidades do interior quanto até mesmo nas capitais dos Estados do Centro-Oeste, em que também predominou rouge ( $85 \%$ das ocorrências), uma vez que, embora com índice populacional maior que das demais cidades, as capitais concentram a administração dessa economia.

Explicando melhor: dentre as localidades que integram a rede de pontos do ALiB no Centro-Oeste ${ }^{10}$, apenas Aripuanã (MT) tem sua formação datada do século $\mathrm{XX}$. Dentre as demais, algumas tiveram sua história ligada à pecuária, ciclo econômico iniciado já na segunda metade do século XIX com a aquisição de fazendas para a

\footnotetext{
9 Tais considerações dizem respeito ao Centro-Oeste brasileiro, região tratada por este estudo. Todavia, resultados das capitais brasileiras, como mencionado neste texto, também revelam resultados semelhantes.

10 Cf. a relação das localidades que compõem a rede de pontos do ALiB em $<$ https://alib.ufba.br/sites/alib.ufba.br/files/rede_de_pontos.pdf $>$.
} 
criação de gado, em grande parte por mineiros que se fixaram no Brasil Central - como é o caso de Campo Grande (MS), Alto Araguaia (MT), Quirinópolis e Jataí (GO). Já a maioria das cidades do interior da região Centro-Oeste, que compõe a rede de pontos do Projeto $\mathrm{ALiB}$, tem como elemento motivador de povoamento a mineração, tanto no que concerne à descoberta de jazidas e à consequente extração (Cuiabá, Cáceres, Vila Bela da Santíssima Trindade, Diamantino, Poxoréu (MT) e Catalão, Goiás, Porangatu e São Domingos (GO)), quanto à descoberta de caminhos fluviais alternativos para o escoamento da produção (Barra do Garças (MT) e Nioaque (MS)). A segurança das fronteiras também motivou o surgimento de núcleos populacionais (Ponta Porã, Corumbá (MS) e Aruanã (GO)), entre os séculos XVII e XIX.

Atualmente, a região continua se destacando pela lida com o gado e, dada a escassez de minérios, também passou a ser importante para o agronegócio no cultivo de grãos, diferenciando-se, pois, de polos industriais e de serviços. Nesse sentido, a natureza do trabalho desenvolvido, as condições geográficas e mesmo as históricas fazem com que esse certo isolamento seja refletido em conservadorismo linguístico, pois essa relação "[...] parece justificar o fato de o vocabulário do grupo não ser marcado por grandes inovações" (ISQUERDO, 1998, p. 104).

Ratificam essa hipótese os dados analisados do ponto de vista diassexual. Haja vista o referente se tratar de um cosmético de uso feminino, aventa-se a hipótese de ele ser mais conhecido por elas, ficando a cargo do homem, talvez, apenas observar o uso por parte das mulheres da casa. Vejamos o Gráfico 7:

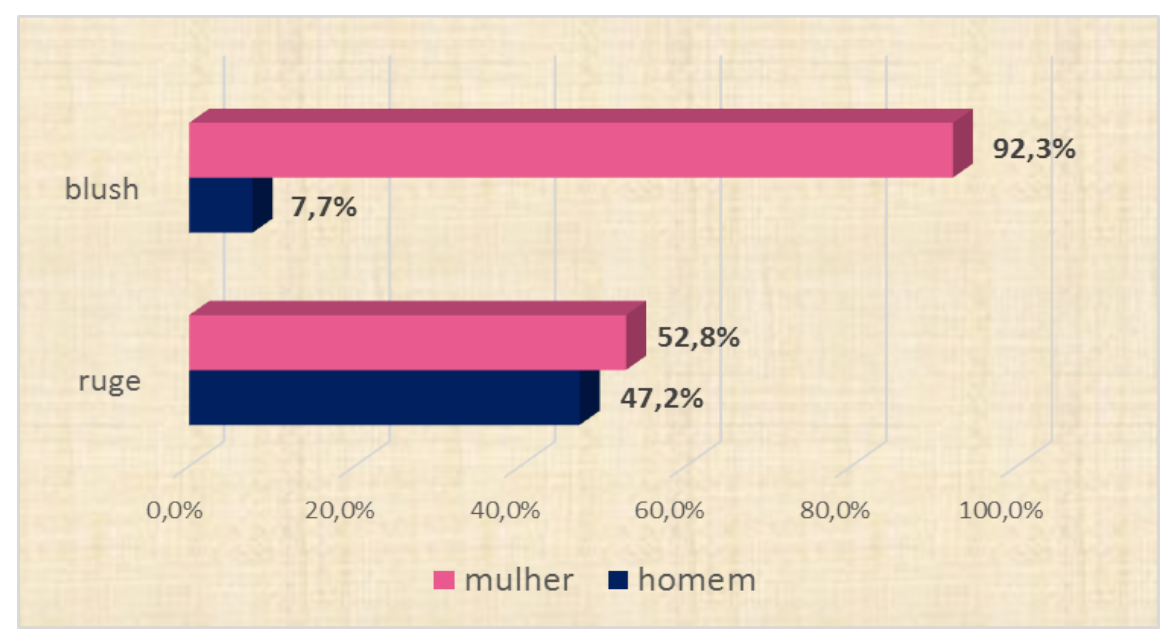

Gráfico 7. Produtividade de rouge e blush no Centro-Oeste/Projeto ALiB segundo a variável sexo, informantes de Ensino Fundamental

Fonte: Banco de Dados do ALiB. Elaborado pela autora

Nota-se que a unidade léxica blush se restringe quase que totalmente à fala das mulheres, ainda dominada por rouge, por seu turno. E ainda há que se considerar que o único registro de blush no universo masculino, na verdade, deve-se ao fato de termos associado tal item lexical à variante bronze, proferida pelo jovem mato-grossense de Alto Araguaia (MT). Podemos então considerar que o domínio de blush no vocabulário feminino $(92,3 \%)$ se deva ao maior contato com esse item, hoje à venda com esse nome, que substituiu, pelo menos comercialmente, o rouge. 
Assim, também a predominância de rouge em ambos os sexos, enfraquecendo a produtividade de blush ao restringi-los apenas ao vocabulário ativo de 12 das 40 mulheres entrevistadas (no universo feminino, isso equivale a $30 \%$ ), pode revelar marcas de conservadorismo linguístico, refletindo um léxico passado de geração a geração. Somam-se a essa afirmação os diversos comentários de informantes presentes nos inquéritos, como ilustram os seguintes: "antigamente era rouge" (mulher, faixa etária II, Alto Araguaia-MT), ou revelando a consciência da mudança linguística: "Rouge. Era pra ficar bem rosadinho assim, mas acho que... agora é blush, ficou mais chique" (mulher, faixa etária II, Goiânia-GO), ou mesmo demonstrando o uso por pessoas mais velhas: "de primeiro falava rouge: 'ah, vou pass, vou comprar um rouge pra passar', né?” (mulher, faixa etária II, Aruanã-GO), além de outros.

O último comentário, inclusive, associado a outros aqui analisados, pode relacionar o conservadorismo linguístico à rede de relacionamentos dos informantes com seus familiares, círculo social e demais pares. A rede social estabelecida entre os moradores do Brasil Central parece contribuir para o comportamento linguístico ora demonstrado, mesmo porque a identidade de um grupo de falantes agrega também a norma linguística em uso. Esse princípio mostra-se bastante pertinente para esta análise uma vez que, não raras vezes, citou-se que já foi ouvido da mãe ou da avó determinada unidade léxica, assim como as relações familiares ainda muito próximas mesmo com gerações passadas, como com as avós, pode auxiliar a manutenção de vocábulos típicos de outros momentos.

Além disso, com questões geográficas particulares frente aos grandes centros que ocasionam atividades econômicas como a lida com o gado e o agronegócio, a norma linguística parece ser influenciada por esse relativo isolamento, mantendo ativas no léxico palavras com datação mais antiga.

Assim, pode-se concluir que fatores como a história social, econômica e cultural da localidade, associada à relação entre seus membros, pode influenciar fortemente a norma linguística em uso em dados espaços.

\section{À guisa de uma conclusão}

Iniciando o tópico cuja motivação é refletir sobre o objeto de estudo deste artigo, acreditamos ser importante seguir os preceitos de Sapir, para quem "[...] o estudo cuidadoso de um dado léxico conduz a inferências sobre o ambiente físico e social daqueles que o empregam" (SAPIR, 1969, p. 49). Mesmo porque essa proposição reflete o que acreditamos ser a língua: um produto social, meio pelo qual as pessoas entendem sua realidade e a transmitem, junto a crenças, hábitos e tradições.

O universo dos dados aqui analisados revelou essa intrínseca relação entre léxico e sociedade, léxico e cultura, uma vez que este trabalho demonstrou que a unidade léxica rouge, datada ainda do século XII, está presente na fala de todos os habitantes, jovens ou não, homens e mulheres ( $81,6 \%$ das ocorrências). Esse comportamento linguístico pode ser mais bem esclarecido se tomarmos as questões sócio-históricoeconômicas das localidades, que tiveram raízes no extrativismo mineral e na pecuária e mesmo hoje permanecem com o agronegócio como principal fonte de renda, tendo em vista que isso pode acarretar certo isolamento sociocultural, ajudando a manter aspectos 
anteriores da língua ainda em uso no Português do Brasil, aqui representado pela fala do Centro-Oeste brasileiro.

Isso se confirma com a baixa produtividade de blush, variante utilizada comercialmente para nomear o referente em pauta, mas que alçou apenas $18,4 \%$ de produtividade no universo de dados, ficando ainda quase restrita ao universo feminino (92,3\% dos registros de blush foram documentados na fala de mulheres). Isso demonstra que, mesmo estando presente no mercado cosmético atual e tendo sua datação mais recente (1969), blush é preterida no uso vocabular da amostra de falantes da região Centro-Oeste, provavelmente a partir das hipóteses já apresentadas.

Também a ocorrência de carmim parece demonstrar um estágio ainda mais anterior da norma linguística. Mesmo com a baixa produtividade, o comentário sobre esse item lexical demonstra a consciência do falante frente às mudanças por que passa a língua.

Enfim, buscou-se demonstrar como os estudos lexicais têm ajudado a documentar a língua em uso, neste caso representada pelo vocabulário dos falantes do Brasil Central entrevistados pelo Projeto Atlas Linguístico do Brasil, tão particular, por vezes, em certas regiões, como pode ser conhecido a partir dos dados em tela. Além disso, confirmou-se a importância das relações sociais, econômicas e culturais como fator determinante para as escolhas lexicais dos falantes, tendo em vista que:

[...] o estudo da linguagem não pode renegar a interação entre o social e o individual que se realiza ao nível do ato de fala; e, mais do que isso, a concepção de língua que fundamente esse estudo tem que comportar em si a dinamicidade dessa interação (LUCCHESI, 1998, p. 56).

Esperamos, dessa forma, contribuir para com as pesquisas linguísticas, bem como auxiliar na documentação, no conhecimento e mesmo no respeito às variedades linguísticas presentes no Português do Brasil, que dão cor local a este idioma e que em muito refletem o próprio modo de ser e de viver tão típico dos brasileiros, aqui representados por habitantes das 24 localidades do Centro-Oeste.

\section{REFERÊNCIAS}

ACADEMIA DAS CIÊNCIAS DE LISBOA. Dicionário da língua portuguesa contemporânea. v. I, Lisboa: A-F, 2001.

AULETE, C. Dicionário Contemporâneo da Língua Portuguesa. Versão eletrônica. Rio de Janeiro: Editora Lexikon, 2006.

BIDERMAN, M. T. de C. Teoria lingüística: lingüística quantitativa e computacional. Rio de Janeiro: Livros Técnicos e Científicos, 1978.

. Dimensões da palavra. Filologia e Linguística Portuguesa, n. 2, p. 81-118,

$1998 . \quad$ Disponível em:

$<$ http://dlcv.fflch.usp.br/sites/dlcv.fflch.usp.br/files/Biderman1998_0.pdf >. Acesso em: 20 mar. 2016.

BORTONI-RICARDO, S. M. Manual de Sociolinguística. São Paulo: Contexto, 2014. 
CAMACHO, R. G. Sociolingüística II. In: BENTES, A. C.; MUSSALIM, F. (Org.). Introdução à lingüística: domínios e fronteiras. v. 1. 5. ed. São Paulo: Cortez, 2005. p. 49-75.

CARDOSO, S. A. M. Reflexões sobre a Dialectologia. In: ISQUERDO, A. N. (Org.). Estudos geolingüisticos e dialetais sobre o português. Campo Grande: Editora UFMS, 2008. p. 13-31.

Geolinguística. Tradição e Modernidade. São Paulo: Parábola Editorial, 2010.

CARDOSO, S. A. M. et al. Atlas Linguístico do Brasil. Londrina: EDUEL, 2014.

CARDOSO, W.; CUNHA, C. Estilística e gramática histórica: português através de textos. Rio de Janeiro: Tempo Brasileiro, 1985.

COMITÊ NACIONAL DO PROJETO ALIB. Atlas Lingüístico do Brasil: questionário 2001. Londrina: Eduel, 2001.

CUNHA, A. G. da. Dicionário etimológico da língua portuguesa. 4. ed. Rio de Janeiro: Lexikon, 2010.

FAUSTO, B. História do Brasil. 13. ed. 1 reimpr. São Paulo: Editora da Universidade de São Paulo, 2009.

HOUAISS, A. Dicionário Eletrônico Houaiss da Língua Portuguesa, Versão 1.0. Rio de Janeiro: Editora Objetiva, 2001.

ISQUERDO, A. N. Vocabulário regional da Amazônia acreana. Alfa, São Paulo, 42 (n. esp.), p. 93-107, 1998.

LABOV, W. Sociolinguistic Patterns. Philadelphia: University of Pensylvania Press, 1972.

LUCCHESI, D. Sistema, mudança e linguagem: um percurso da linguística neste século. Lisboa: Colibri Artes gráficas, 1998.

MELO, G. C. de. A língua do Brasil. 2. ed. Rio de Janeiro: Editora FGV, 1971.

MOTA, J. A.; CARDOSO, S. A. M. Para uma nova divisão dos estudos dialetais brasileiros. In: MOTA, J. A.; CARDOSO, S. A. M. (Org.). Documentos 2: projeto Atlas Linguístico do Brasil. Salvador: Quarteto, 2006. p. 15-26.

PAIM, M. M. T.; GUIMARÃES, M. S. Caminhos do projeto ALiB: reflexões sobre a emergência da identidade social de faixa etária. Entrepalavras, Fortaleza, ano 2, v. 2, n. 1, p. 293-305, jan./jul. 2012.

PROJETO ALIB. ATLAS LINGUÍSTICO DO BRASIL. Histórico. Disponível em: $<$ https://alib.ufba.br/hist\%C3\%B3rico $>$. Acesso em: 20 jun. 2016.

SANDES, N. F. Memória e história de Goiás. SANDES, N. F. (Org.). In: Memória e região. Brasília: Ministério da Integração Nacional: Universidade Federal de Goiás, 2002. p. 17-35.

SANTOS, T. F. R. A mudança adjetivo/nome > nome/adjetivo e o conservadorismo da fala rural goiana. 2008. 576 f. Tese (Doutorado em Linguística) - Faculdade de Letras, Universidade Federal de Minas Gerais, Belo Horizonte, 2008. Disponível em: $<$ http://www.bibliotecadigital.ufmg.br/dspace/bitstream/handle/1843/DAJR88QG9G/750d.pdf?sequence=1>. Acesso em: 26 mar. 2016. 
SAPIR, E. Lingüística como ciência. Rio de Janeiro: Editora Livraria Acadêmica, 1969. TAMBA, I. A Semântica. São Paulo: Parábola Editorial, 2006.

VERÍSSIMO, L. F. $E$ tudo mudou... Disponível em: $<$ https://poemasfrasesetextos.wordpress.com/cronicas-textos/luis-fernando-verissimo/>. Acesso em: 20 jun. 2016.

Recebido em: 17/10/2016

Aprovado em: 05/03/2017 